tion in North America, and whether a net public health benefit was expected from reintroduction of this amphetamine product.

Why are the scientific data that form the basis of regulatory decisions in Canada considered proprietary? The New Drug Committee should have met in public, its reports and transcripts should have been posted on the Web, and other scientists, health care professionals and members of the public should have been allowed to make submissions. The committee's report provides a glimpse of the thinking behind regulatory decision-making. A glimpse is not enough: full participation and access to information are needed.

\section{Pierre Biron}

Honorary Professor

Department of Pharmacology

Faculty of Medicine

Université de Montréal

Montréal, Que.

Barbara Mintzes

Postdoctoral Fellow

Department of Anaesthesiology,

Pharmacology and Therapeutics

University of British Columbia

Vancouver, BC

Joel Lexchin

Associate Professor

School of Health Policy and

Management

York University

Toronto, Ont.

\section{REFERENCES}

I. Kondro W. Inconclusive evidence puts Adderall back on the market. CMAJ 2005;173:858.

2. Levine M, Gow R, Shea S. Report of the Adderall XR New Drug Committee. Available at: www.hc-sc.gc.ca /dhp-mps/alt_formats/hpfb-dgpsa/pdf/prodpharma Indca_rep_cnma_rap_2005-08-25_e.pdf (accessed 2006 Mar 27).

3. Willy ME, Manda B, Shatin D, Drinkard CR, Graham DJ. A study of compliance with FDA recommendations for pemoline (Cylert). J Am Acad Child Adolesc Psychiatry 2002;4I(7):785-90.

Competing interests: None declared.

DOI:I0.I503/cmaj.I060004

\section{Questioning the evidence}

I am writing about a recent article in the CMA Leadership Series on Elder Care, distributed with the Nov. 8, 2005, issue of $C M A J{ }^{1}$

As one who has been studying the research and marketing related to Alzheimer's disease (AD) treatments for nearly a decade, I found the article disturbing. The discussion on the benefits of the AD drugs are nearly opposite to what the best evidence says.

The writer states that "In numerous randomized clinical trials (RCTs), cholinesterase inhibitors (ChEIs) have consistently been shown to improve or delay the decline of cognitive functioning, delay the emergence of challenging behaviours and slow the loss of activities of daily living. In RCTs, benefits have been shown to last over a period of up to 2 years, with data from open-label trials suggesting a longer benefit." ${ }^{1}$

However, the company-sponsored trials upon which this statement relies are problematic and overstate the case for the role of these drugs in managing $\mathrm{AD}$. The latest meta-analyses find that the effects of ChEIs are marginal to non-existent. ${ }^{2}$

I found the discussion of side effects almost laughable: "Before initiating treatment, physicians should discuss reasonable expectations with the patient and their caregiver. Patients should be warned of possible side effects, noting that they are often mild and fleeting." 1

When I have read the monographs of the key $\mathrm{AD}$ drugs, the effects such as nausea, vomiting, anorexia and stomach upset are as high as 30\%. In fact some commentators have joked that these drugs are more effective as weight-loss pills than altering the rate of cognitive decline. Here is an example of some of the side effects related to an $\mathrm{AD}$ drug, rivastigmine (taken from the product monograph):

Exelon's use is associated with significant gastrointestinal adverse reactions, including nausea and vomiting, anorexia, and weight loss. In the controlled clinical trials, $47 \%$ of the patients treated with an Exelon dose in the therapeutic range of 6 to 12 $\mathrm{mg} /$ day developed nausea (compared with I $2 \%$ in placebo). A total of $31 \%$ of Exelon-treated patients developed at least one episode of vomiting (compared with $6 \%$ for placebo). The rate of vomiting was higher during the titration phase ... than in the maintenance phase ... Five percent of patients discontinued for vomiting, compared to less than $\mathrm{I} \%$ for patients on placebo. ${ }^{3}$
I don't know any physician who would dismiss these effects as "mild and fleeting."

I would echo the words of one researcher, Jason Karlawish, who remarked on a flawed study on donepezil with: "Would it be churlish to wonder out loud how this paper is different from an advertisement?" ${ }^{4}$ I have to admit I am on the verge of losing a lot of respect for the $C M A J$ unless it stops distributing this kind of clearly biased and non-evidence-based fluff. I cannot see how it is in the best interests of physicians to have such articles published under the banner of CMAJ.

\section{Alan Cassels}

Pharmaceutical Policy Researcher School of Health Information Science University of Victoria

Victoria, BC

\section{REFERENCES}

I. Keren R. Managing Alzheimer's disease. Elder care: issues and options for Canadian physicians 2005. CMA Leadership Series; 2005.

2. Kaduszkiewicz H, Zimmermann T, Beck-Bornholdt $\mathrm{HP}$, et al. Cholinesterase inhibitors for patients with Alzheimer's disease: systematic review of randomised clinical trials. BMJ 2005;33I(7512):32I-7.

3. Exelon (rivastigmine tartrate) [product monograph]. East Hanover (NJ): Novartis Pharmaceutical Corporation; 2006.

4. Karlawish JH. Donepezil delay to nursing home placement study is flawed. J Am Geri Soc 2004;52: 845 .

DOI:I0.I503/cmaj.I050255

\section{[The author responds:]}

Mr. Cassels raises 2 major objections relating to comments I made about the treatment of AD with ChEIs. ${ }^{1}$ His first objection refers to the quality of the evidence supporting the use of these medications. The second objection relates to the tolerability of these drugs, specifically, addressing the issue of gastrointestinal side effects.

With regards to the evidence supporting the use of ChEIs, to date there are 22 RCTs with ChEIs published in leading peer-reviewed journals, including the New England Journal of Medicine, the Journal of the American Medical Association, the Lancet, Neurology and $J A G S$, that have consistently shown a modest benefit for patients with $\mathrm{AD}$. All these trials were carried out under 
Good Clinical Practice and International Conference of Harmonization guidelines. ${ }^{2}$ Based on a systemic review of these trials, the Canadian Consensus Conference on Dementia guidelines ${ }^{1}$ unequivocally recommended that all patients with mild to moderate $\mathrm{AD}$ be offered a trial of one of these drugs. Mr. Cassels argues that a recently published systematic review by Kaduszkewicz in $B M{ }^{\beta}$ is "best evidence" and, in his view, this review not only negates the evidence from the aforementioned published clinical drug trials but also 4 previously published meta-analyses of $\mathrm{ChEIs}^{4-7}$ and the Cochrane reviews, ${ }^{8-10}$ all of which have concluded that ChEIs offer a modest benefit to patients with $\mathrm{AD}$ in the domains of cognition, behaviour, function and caregiver burden. In September 2005 the Canadian Coordinating Office for Health Technology Assessment (CCOHTA) published a systematic review of this class of drugs claiming a modest impact on functional performance and global outcomes. ${ }^{11}$ Lastly, in a recent survey conducted in the UK in 2295 patients with AD treated with ChEIs and the caregivers, 1569 (68\%) of people who had been treated with at least one of the ChEIs stated that the treatment had worked. The Io most frequently reported benefits included being more aware and more active, calmer, taking more interest in things, improved conversation, better quality of life and increased confidence, in addition to the improvements usually evaluated in clinical trials. ${ }^{12}$ No study is without its flaws, but to write off all of the evidence supporting the use of ChEIs in the treatment of $\mathrm{AD}$ based on one critical review seems unreasonable. The Health Protection Branch of Health Canada has weighed the evidence and approved the use of these drugs for the treatment of mild to moderate $\mathrm{AD}$, and most provincial and private drug benefit programs provide financial coverage for their use.

ChEIs are considered to be safe and well tolerated. The CCOHTA report concluded that these drugs have not shown an increased risk of serious adverse events or death. With regard to side effects, Mr. Cassels bases his comments on one of the drug's (rivastigmine) product monograph, citing a high inci- dence of gastrointestinal side effects and compares the drugs to "weight loss pills." Gastrointestinal side effects are known to occur in this class of drugs, but their prevalence as reported in product monographs is based on data from clinical drug trials, which is greater than what is seen in clinical practice. This is for two reasons: first, in clinical drug trials a side effect is reported regardless of its frequency and severity: second, dosages are increased using forced titration schedules. In clinical practice, physicians can reduce the impact of side effects through slower titration and dose adjustments. Also, they can address the patient's treatment expectations and potential side effects by providing education and support. Having personally treated hundreds of patients with these drugs, nausea, vomiting and weight loss have been infrequent complaints that have rarely necessitated discontinuation of treatment, and when treatment is stopped these side effects generally resolve quickly.

Mr. Cassels' comments echo a number of recent critical reviews of ChEIs, including the preliminary report from the UK's National Institute of Clinical Excellence and the University of British Columbia's Therapeutics Initiative. These reports question the cost effectiveness of treating patients with ChEIs, claiming that the drugs, at best, have a modest effect and do not delay milestones such as time to institutionalization. As your readers know, $\mathrm{AD}$ is a progressive neurodegenerative disease for which there is no cure. It affects over 300 ooo Canadians, robbing them of their self, stripping the, of their independence, leading them to institutionalization and death. In doing so, $\mathrm{AD}$ places a huge burden on patients, their caregivers and society at large. Taking this into consideration, treatments that offer even modest benefits can have an important impact on the quality of life of patients and caregivers affected by this disease.

\section{Ron Keren}

Clinical Director

University Health Network

Memory Clinic

Toronto Western Hospital

Toronto, Ont.

\section{REFERENCES}

I. Keren R. Managing Alzheimer's disease. Elder care: issues and options for Canadian physicians 2005. CMA Leadership Series; 2005.

2. Patterson CJS, Gauthier S, Bergman H. Canadian Consensus Conference on Dementia: a physician's guide to using the recommendations. CMAJ I999; I6o(I2): $1738-42$.

3. Kaduszkiewicz H, Zimmermann T, Beck-Bornholdt HP, et al. Cholinesterase inhibitors for patients with Alzheimer's disease: systematic review of randomised clinical trials. BMJ 2005;33I(75I2): 32I-7.

4. Lingler JH, Martire LM, Schulz R. Caregiver-specific outcomes in antidementia clinical drug trials: a systematic review and meta-analysis. J Am Geriatr Soc 2005;53(6):983-90.

5. Ritchie CW, Ames D, Clayton T, et al. Metaanalysis of randomized trials of the efficacy and safety of donepezil, galantamine, and rivastigmine for the treatment of Alzheimer disease. Am J Geriatr Psychiatry 2004; $12(4): 358-69$.

6. Lanctot KL, Herrmann N, Yau KK, et al. Efficacy and safety of cholinesterase inhibitors in Alzheimer's disease: a meta-analysis. CMAJ 2003; I69(6):557-64.

7. Trinh NH, Hoblyn J, Mohanty S, et al. Efficacy of cholinesterase inhibitors in the treatment of neuropsychiatric symptoms and functional impairment in Alzheimer disease: a meta-analysis. JAMA 2003;289(2):210-6.

8. Birks JS, Harvey R. Donepezil for dementia due to Alzheimer's disease. Cochrane Database Syst Rev 2003;3:CDoorigo.

9. Birks JS, Grimley Evans J, Iakovidou V, et al. Rivastigmine for Alzheimer's disease. Cochrane Database Syst Rev 2000;4:CDoorigI.

Io. Olin J, Schneider L. Galantamine for Alzheimer's Disease. Cochrane Database Syst Rev 2002;3: CDool747.

II. Perras C, Shukla VK, Lessard C, et al. Cholinesterase inhibitors for Alzheimer's disease: a systematic review of randomized controlled trials [Technology report no 58]. Ottawa: Canadian Coordinating Office for Health Technology Assessment; 2005.

I2. Ballard C, Burns A, Sharp S, et al., Oct. 2I, 2005 response to: Kaduszkiewicz H, Zimmermann T, Beck-Bornholdt $\mathrm{H}$, et al. Cholinesterase inhibitors for patients with Alzheimer's disease: systematic review of randomised clinical trials. BMJ 2005; 33I:32I-7. Available: http://bmj.bmjjournals com/cgi/eletters/33I/75I2/32I (accessed 2006 Mar I6).

DOI:I0.1503.cmaj.1060oI3 